University of Montana

ScholarWorks at University of Montana

2001

\title{
The Dynamic, Emergent, and Multi-Phasic Nature of On-Site Wilderness Experiences
}

\author{
William T. Borrie \\ University of Montana - Missoula, bill.borrie@umontana.edu \\ Joseph W. Roggenbuck \\ Virginia Polytechnic Institute and State University
}

Follow this and additional works at: https://scholarworks.umt.edu/soccon_pubs

Part of the Leisure Studies Commons

Let us know how access to this document benefits you.

\section{Recommended Citation}

Borrie, William T. and Roggenbuck, Joseph W., "The Dynamic, Emergent, and Multi-Phasic Nature of OnSite Wilderness Experiences" (2001). Society and Conservation Faculty Publications. 8. https://scholarworks.umt.edu/soccon_pubs/8

This Article is brought to you for free and open access by the Society and Conservation at ScholarWorks at University of Montana. It has been accepted for inclusion in Society and Conservation Faculty Publications by an authorized administrator of ScholarWorks at University of Montana. For more information, please contact scholarworks@mso.umt.edu. 


\title{
The Dynamic, Emergent, and Multi-Phasic Nature of On-Site Wilderness Experiences
}

\author{
William T. Borrie \\ School of Forestry, University of Montana, Missoula, MT \\ Joseph W. Roggenbuck \\ Department of Forestry, Virginia Tech, Blacksburg, VA
}

Feelings and cognitions of leisure may not only be dynamic during the course of the total outdoor recreation engagement, they may be dynamic, emergent, and multi-phasic during the on-site phase. Experience Sampling Method data were collected from a sample of wilderness visitors multiple times during a visit to the Okefenokee National Wildlife Refuge. Four modes of environmental experience (focus on self, others, task, and environment) and four aspects of wilderness experience (a combined oneness/primitiveness/humility variable, timelessness, solitude, and care) were measured. Univariate and multivariate repeated measures analyses demonstrated significant change from the entry, through immersion, to the exit phases of the wilderness experience. This experiential change included greater focus on the environment and on self/introspection at the exit compared to the entry phase, and less focus on others/ social acceptance during the immersion phase. Scores on humility/primitiveness/oneness were higher at both the immersion and exit phases than during entry, and care for the wilderness was higher during the exit phase than during entry. Implications of findings for understanding the complex nature of leisure experiences are provided.

KEYWORDS: Leisure experiences, wilderness recreation, recreation experience phases, human-nature transaction, experience sampling method

\section{Introduction}

A recent special issue of $J L R$, devoted to leisure as having multiple phases, noted that leisure might best be viewed as emerging states of mind, as a sequence of transactions between individuals and their environment, as personal stories with temporal and spatial qualities, and as a lived experience (Stewart 1998). Given this perspective on leisure, Stewart cites several disconnections between multiphase leisure and philosophical, theoretical, and methodological traditions within the leisure research community. He then goes on to issue challenges to the leisure research community if it is to embrace the revised perspective.

The study reported here on the multiphasic nature of trips into the Okefenokee Wilderness in southern Georgia begins to address some of Stew-

\footnotetext{
Address correspondence to: Bill Borrie, School of Forestry, University of Montana, Missoula, MT 59812-0576. Email: borrie@forestry.umt.edu

The authors acknowledge, with gratitude, the help and financial support of the Aldo Leopold Wilderness Research Institute on this study. Also, the authors thank the staff of the Okefenokee National Wildlife Refuge for their logistical support and assistance.
} 
art's challenges. The first is that leisure is purported to not simply be a state of mind; it is instead states of mind. These states of mind might, for example, include several types of positive emotions, personal meanings associated with the challenges of leisure environments, and cognitions related to such things as way-finding during leisure travel. Second, these multiple states are dynamic, evolving, and dependent in part on context. Finally, research methods that attempt to measure the dynamic, evolving, and contextual states of leisure must necessarily be innovative and deserve further experimentation and development.

Thus, this study employed innovative research methods and technologies to address three basic questions:

- Research Question 1: What leisure states of mind are measurable during a wilderness experience?

- Research Question 2: Are these leisure states of mind dynamic and evolving during the course of a wilderness experience?

- Research Question 3: Can the leisure states of mind be characterized as multiphasic during the on-site experience? More specifically, are there distinct entry, immersion, and exit phases that occur during the on-site experience?

\section{Study Site}

The 354,000-acre Okefenokee Wilderness seems almost an ideal site to address the study questions. First of all, wilderness areas are almost by definition complex, diverse environments. Of all places on earth, they are places where the evolutionary forces of nature are most able to operate freely. At least at the landscape level, this would tend to promote conditions or contexts of diversity. This provides recreationists with a variety of challenging and calming stimuli. Okefenokee Wilderness is also a swamp, a wetland wilderness of alligators, panthers, and black bears. Such ecosystems have both very high levels of biodiversity and are strange environments for humans. The process of entry into such an environment, becoming acclimatized to it, and then leaving it would seem to provide ample opportunity for changes and phases in states of mind or states of leisure. Okefenokee is also big; reaching its interior and finding its story takes time and effort. During hours and days of paddling, there is ample opportunity for introspection, for sharing emotions with companions, for focus on the task of travel, or for attending to the natural environment. The Okefenokee experience would seem to be complex, emergent, and to evolve across time.

The study site is also a unit of the National Wilderness Preservation System. As such, according to the Wilderness Act of 1964, it is managed to provide opportunities for solitude or a primitive and unconfined type of recreation (PL 88-577). At first glance, this legal mandate may seem to limit the complexity of leisure experiences. Indeed, managers at Okefenokee in their efforts to limit the negative impacts of recreationists on naturalness and on opportunities for solitude, have limited the number of overnight users, assigned travel routes, and assigned camp spots. But management is a 
balancing act because there is also a mandate for "unconfined recreation," for allowing the human-nature transaction to unfold freely. Indeed, day use at the margins of the wilderness is largely unrestricted.

Also, there have been increased calls for a more complete understanding of the total experience in legally classified wilderness. Former Congressman Vento (1990) once called for more effort to focus on existing wilderness areas and to better understand their benefits to people. Patterson, Williams, Watson, and Roggenbuck (1998) used a hermeneutic approach to studying the nature of wilderness experiences, and found challenge, closeness to nature, decisions not faced in everyday environments, and stories of nature to most completely describe the nature of experiences among canoeists in nearby Florida's Juniper Prairie Wilderness.

Finally, Okefenokee seems ideal for the innovative research methodology required for lived experience sampling. Management restrictions generally permitted us to know in advance what parties were entering at what access points on which dates, to know what routes groups were taking through the swamp, and to know on what dates and locations they were exiting the swamp. This facilitated the distribution of data collection instruments at entry points and their collection at the exit points.

\section{Literature Review}

\section{Multiple Phases of Leisure States}

Some of the very early recreation theorists (e.g., Clawson and Knetsch 1966) described the outdoor recreation experience as multiphasic. They viewed the total experience as typically consisting of five phases: anticipation, travel to, the actual on-site experience, the travel-back phase, and the recollection phase. Clawson and Knetsch argued that outdoor recreationists gain satisfaction or dissatisfaction from each phase of the experience. They suggested, barring failure in the outdoor recreation delivery system, that there might be a common pattern of increasing joy, satisfaction, or benefit from anticipation through travel to and including the on-site experience. There may be a drop in satisfaction during the travel-back phase, but then considerable recovery in benefits during the recollection phase.

This dynamic view of leisure has been widely taught in introductory outdoor recreation courses. But it has been seldom tested and has had little influence in guiding the development of leisure theory and research (Stewart 1998). Why this is so is not entirely clear. Perhaps the focus of the Clawson and Knetsch model on economic demand and benefits limits its usefulness for understanding leisure states. Perhaps the failure of the model to recognize that leisure states are likely dynamic within the five phases limits its usefulness for the leisure research community.

\section{The Dynamic Nature of On-Site Leisure States}

Like the Clawson and Knetsch model of the multiple phases of outdoor recreation, published work on the dynamic nature of the on-site leisure ex- 
perience began in the 1960s. For example, Klausner (1967) examined fear and enthusiasm over 14 stages of a sport parachuting experience and found that these two emotions changed and evolved during the event. Recreationists' fear increased continuously and enthusiasm decreased slightly while they were at the site but before they jumped. Immediately after jumping from the plane and before landing, participants experienced intense enthusiasm and low fear. During landing, fear again increased. After participants landed and removed their parachutes, their fear subsided quickly and enthusiasm reached its peak.

Little attention was given to the dynamic nature of leisure during the 1970 s and 1980s, but research on this topic began to flourish in the 1990s. For example, Hull, Stewart, and their associates (Hull 1990; Stewart 1992; Hull, Stewart and Yi 1992; Hull and Michael 1995; and Hull, Michael, Walker, and Roggenbuck 1996) focused on mood as the primary measure of the leisure state of short-term visits to nature places. They generally found that mood varied across stages of the on-site visit and that environmental and person variables shaped at least some moods during the recreational engagement. In particular, negative moods like anxiety often decreased during short visits to urban parks or on short walks along rural roads, but then typically returned to their starting point at the end of the activity. In contrast, destination-oriented day hikers walking through a natural area at the edge of Colorado's Maroon Bells Wilderness retained high positive and less negative emotions upon reaching their goal (the goal was often a vista point farthest away from the road and deepest into the wilderness).

Celsi, Rose, and Leigh (1993) found that, for participants in skydiving, benefits such as flow, identity generation, mastery, feeling of catharsis, and attitudes toward risk changed and evolved within each recreation event. Among other things, Lee, Datillo, and Howard (1994) asked study participants to describe their feelings, likes, and dislikes during engagement in selfselected leisure activities. During the actual recreational activity, participants frequently mentioned positive emotions and benefits, but at the same time described feelings of exhaustion, nervousness, disappointment, frustration, and guilt.

\section{The Multi-phasic Nature of On-Site Wilderness Experiences}

Some of the most innovative and comprehensive real-time measures of the dynamic nature of leisure states have been completed in wilderness or wilderness-like settings. Some of these studies have suggested distinctive phases of leisure states across time. For example, Kaplan and Talbot (1983) and Talbot and Kaplan (1986) studied the experiences of adolescent participants of an extended Outdoor Challenge Program in the wilderness of the Upper Peninsula of Michigan. The structure of this program fostered the participants' attention to the environment itself and on individual reflection. As participants quickly learned the skills, knowledge, and approaches needed to cope in the wilderness environment, worries about the environment became significantly less important. With time, perceptual responses to the 
environment tended to include more detail, and emotional responses tended to be more intense. Toward the middle of the course, many participants described a sense of revelation as the environment and the self were newly perceived and appreciated, developing into feelings of awe and exhilaration. Increased understanding of the natural environment and a greater sense of relationship to the surrounding area were also reported.

These findings suggest that perceptual changes occur in wilderness, that these changes in perception facilitate the benefits received from the wilderness experience, and that at least for wilderness programs which focus on reflection and the environment, these perceptions and benefits evolve across time. The first category of benefits, typically unfolding a few days into the experience, includes a greater awareness of the person-environment relationship, and a fascination with what is observed in nature. The second class of benefits, building on the first and occurring around one-third of the way through the multi-day experience, focuses on an increase in self-confidence, less distraction, and a greater sense of coherence. The third major benefit category, adding to both the first and second, occurs around the middle of the trip and features feelings of compatibility, relatedness to the surrounding environment, and a larger sense of contemplation. At this stage, participants have "discovered a different self in the wilderness setting-a self less conflicted, more integrated, more desirable" (Kaplan \& Talbot 1983, p. 195).

Scherl $(1989,1990)$ used personal narratives in logbooks to study the day-to-day affective states, perceptions, and cognitions of adult participants on a nine-day Outward Bound program in Australian wilderness. A predominance of three particular aspects of the wilderness experience were found on this shared and facilitated course: emotional responses/level of arousal, a balancing between self and group, and an awareness that physical and mental efforts were essential components of the experience. While the saliency of the wilderness activities was found to be high throughout, the other domains of the wilderness experience fluctuated in importance. A focus on self was seen to be central at points of time when coping was required or when the rest of the group was not available for support. For example, on the last day of the program, when participants were reflecting back on all that had been achieved, self-awareness was dominant. Similarly, participants' level of excitement was very high at the conclusion of the trip, but they were also sad that the experience was over and that all would be returning to civilization and going their own ways. Focus on the environment was better achieved during such quiet periods as the solo day, when subjects were not stressed or coping with high levels of physical, social, or emotional challenge. In general, the programmed sequence of activities on the course seemed to profoundly influence participant experiences.

Arnould and Price (1993) used a combination of qualitative and quantitative approaches to study the dynamic nature and benefits of a lengthy raft trip on the Colorado River in the Grant Canyon. During the trip, participants experienced huge mood swings, including apprehension, fear, frustration, exhilaration, and awe. Their narratives contained numerous allusions 
to self-discovery, communion with nature, and connection with others, as well as references to feelings of adventure, challenge, and excitement. Qualitative research findings indicated that, as the long trip progressed, participants experienced a trend to deeper connections/knowledge of self, of others on the trip, and of nature.

McIntyre and Roggenbuck (1998) and McIntyre (1998) used the Experience Sampling Method to obtain real-time measures of the dynamic nature of outdoor recreation. The McIntyre and Roggenbuck study reported the changing nature of an adventure recreation experience as it unfolded during a black-water rafting trip in a cave in New Zealand. Key variables used to describe the person-nature transaction were focus of attention, mood states, feelings of connection with nature, and perception of risk and competence. These were measured as participants put on wet suits at the base camp, at the entrance to the cave, at a waterfall in the cave, during a quiet float in darkness under a ceiling of glow-worms, and in the vehicle going back to camp. Scores on study variables varied with environmental context, and also across time and phase of the experience. For example, focus on nature and focus on task were high throughout the trip in the cave, but they varied depending on the environmental context there. In contrast, scores on both these foci of attention were lower as respondents dressed for the adventure and as they rode in a vehicle through a natural environment back to base camp.

The McIntyre study (1998) randomly beeped canoeists on a wilderness river in Cooloola National Park in Australia and asked them to record their level of activity, focus of attention, and feelings of connection with wilderness at that moment. Somewhat surprisingly, respondents reported focusing most on social acceptance by group members, followed by focus on task, the environment, and on self. Introspection was quite low at all times, but contrary to expectations, was not reported highest during periods of inactivity. Aspects of a wilderness experience measured were those often described by western wilderness philosophers: solitude, primitiveness, oneness, timelessness, and care. Of these, participants recorded high levels of timelessness, moderate levels of care and solitude, but low levels of oneness and primitiveness. But feelings varied considerably depending upon level of activity. Feelings of care for the environment, oneness, and primitiveness were reportedly highest during such active times as walking or canoeing. In contrast, timelessness scores showed highest levels during passive activities. Maintenance activities were least likely to facilitate timelessness, solitude, and oneness with nature.

In summary, recent research on the lived experience of outdoor recreation has made four important contributions: (1) it has contributed to the existing body of literature on the complex nature of leisure; researchers of the lived experience have measured emotion, mood, attention states, feelings of connection with others and nature, attitudes, and cognitions; (2) it has begun to measure the ebb and flow of on-site experiences in real time; this has been accomplished through the completion of journals, personal accounts, or short survey forms at assigned points or random times during the 
experience; (3) it has suggested that changes in leisure states of mind during the on-site experience are partly due to such contextual variables as level of personal activity, type of environment encountered, and time into the experience; and (4) it has hinted that there may be distinctive phases within the on-site experience.

\section{Hypothesized Phases of the On-Site Experience of Okefenokee Wilderness Visitors}

All of the previous studies of wilderness visitors that suggested phases of the on-site leisure experience were guided or mediated trips. Thus, the experience itself, and any dynamic and multi-phasic characteristics of it, might be explained as much by the guides' orchestration of the experience or by the activities called for by the outdoor education program as by time into the experience relative to entry and exit. On the other hand, the general public's unmediated experience in wilderness, the topic of the research reported here, may more likely show patterns of response to wilderness across the duration of the trip. Perceptions, cognitions, and affective responses, while perhaps less trained, are likely more direct, and transactions with the temporal, spatial, and biophysical aspects of the wilderness environment may be more immediate and genuine. The wild nature encountered may be more personal and powerful.

We therefore hypothesized that the experience of Okefenokee visitors is dynamic and emergent and that it can be described as having three distinct phases: entry, immersion, and exit. Wilderness is nature distinct from society, it is the Other, and for many it is foreign. Wilderness is typically not a place with which one has day-to-day familiarity, and for that reason it likely takes most visitors some time to attune to it. When visitors enter wilderness, they may gradually discard many of the concerns of the outside world as they adjust and adapt to the ancient rhythms and demands of the wilderness world. Therefore, in the entry or threshold phase of the wilderness experience, one can envisage a sloughing-off of modern civilization and a refocusing toward the requirements and opportunities of wilderness. Since most wilderness visitors are infrequent visitors, perceptual and survival skills must be relearned. Much of the entry phase likely focuses on learning or readjusting/remembering the use of one's body and equipment for the demands ahead. Visitors gradually learn to see the wilderness for what it is and what it affords. Behavior adjusts to fit what is appropriate and viable given the immediacy of the wilderness environment. And just as much as the wilderness environment demands more attunement, so too does the outside world demand less.

Immersing further into the wilderness experience, visitors may be moving into more of a wilderness way of being. That is, immersed in the wilderness experience with fewer external distractions, recreationists have the opportunity to attend more often to what is immediately at hand. Achieving comfort with ability, the tasks to be carried out, and the affordances of the 
immediate environment would allow opportunity to observe and contemplate the wilderness world and the individual's place in it. As Kaplan and Talbot (1983) suggest, as perceptual ability and confidence in abilities increase, and given the necessary time and space, many may move to contemplation, appreciation, and understanding of the human-environment relationship. These perceptions and revelations would not be expected to immediately fade, but would maintain a salience and importance as the visitor prepares for, and returns to, home and work life.

As the end of the wilderness visit draws near, many visitors might mentally, physically, and emotionally prepare for the return to civilization. Not only are the social and environmental adjustments made during the experience less urgent and less necessarily sustained, but also new behaviors must be re-adopted upon return. That is, visitors begin to lessen the importance of investing in a wilderness identity and begin re-adoption of an outside identity. However, the outside identity may be changed or merged with the wilderness identity (Pohl, Borrie, and Patterson 2000). For example, the acquired feelings and knowledge of self and of the environment may carry on across the wilderness boundary.

\section{Methods}

\section{Study Participants}

Study participants were a convenience sample of Okefenokee Wilderness visitors on 23 days (7 weekend days and 16 weekdays) during the high-use months of October and November 1994. Since all overnight parties needed a permit with an assigned entry point and travel route, some information was known in advance of how many groups would enter and exit the wilderness each day at each of the area's three access points. However, these permit estimates of use were not entirely accurate because of last-minute cancellations, simple no-shows, and day use (which didn't require a permit) at individual access points. Also, because of large distances between the area's three access points, it was not possible for the study's research technician to contact every group of visitors on sample days. Approximately 80 groups entered the wilderness on sample days. Of these, 63 were contacted to participate in the study (47 overnight groups and 15 day-use groups). Only one group refused to participate in the study. Within any sampled group, the research technician conveniently selected one individual at the canoe launching point to complete the data collection instruments.

\section{Characterizing Leisure Experiences in Wilderness}

Of the many aspects of leisure states of mind that researchers before us measured, we chose two: modes of environmental experience and feelings of connection to wilderness.

Mode of experience is the transaction between a person and the environment. It represents one's focus of attention, and Ittelson, Franck and 
O'Hanlon (1978) have suggested that one of five modes might be absorbing at any point during an environmental experience. First, a focus on self or introspection represents the individual concentrating on internal thoughts and processes. This is the degree to which the components of the experience are internalized. In this mode, the experience of the environment is a largely self-centered one, and consists of reflective thought and contemplation. At its logical extension, self-identity is under consideration and construction, and can extend outward to include a sense of "environmental self." The environment ceases to be separate, and at its logical extent becomes part of the self (Ittelson 1978). A focus on others or social acceptance suggests that, for some, the experience in wilderness is primarily a social one. Interactions with friends and/or family, even strangers and the general public, may vary from distant and task-oriented to close, intimate, and casual. In a social wilderness experience, concern about presence (or absence) and response of other people shape the meaning of the moment. A focus on task or task orientation refers to the situations where a participant's actions or activity within the wilderness become the dominant feature. Often, goals and behaviors are the primary way to describe the experience. Other concerns become peripheral because of the intense concentration, struggle or involvement in the task. A focus on nature or environmental awareness is the extent to which people pay attention to the biophysical aspects of the environment. It is the degree to which people are focusing on the natural world out there rather than the world within. It may well be that as people are able to pay attention too much more minute details of the environment, a sense of familiarity and orientation are gained (Ittelson et al. 1978). A focus on emotions or emotional intensity occurs when the environmental experience is primarily influenced and dominated by strong feelings and emotions. Sensations of enjoyment (fun), relaxation or comfort, and satisfaction are all affective modes. Emotional involvement is a significant component of the leisure state (Mannell, Zuzanek, and Larson 1988; Csikszentmihalyi 1975; Samdahl 1991), and other researchers such as Hull et al. (1992) have demonstrated the relevance of emotions to the overall wilderness experience pattern.

The writings of wilderness philosophers like Henry David Thoreau, John Muir, Aldo Leopold, Bob Marshall, and Sigurd Olson (e.g., see Thoreau, 1854, 1862; Muir, 1901, 1911, 1916; Leopold, 1949; Marshall, 1930; Olson, 1956, 1963, 1969, 1976; Warren, 1990) were used to identify the purported fundamental values or aspects of wilderness. The ideas of these writers not only heavily influenced the authors of wilderness legislation but also continue to play a guiding role in the management of wilderness. They likely also influence how current users construct the meaning of the wilderness. Six defining aspects of wilderness were identified from the texts: primitiveness, timelessness, solitude, oneness, humility, and care.

The primitiveness aspect of wilderness relates to its contrast with modern and technological society. In wilderness there is the chance to revisit nature as our ancestors might have found it and to feel part of the past. It is a land 
of challenge, adventure, and for some, hardship. A simpler way of life awaits those who would leave civilization behind, and set forth into the wilderness. Beyond the constraints and responsibilities of society lies the freedom to be wild, perhaps more in tune with the ancient rhythms of life. Wilderness also purportedly allows visitors the opportunity to escape the constraints and pressures of the outside world. In doing so, wilderness visitors can forget the normal pace of life and enter into an experience of unmeasured and uncontrolled time, or timelessness. Within the stillness of wilderness can be found the opportunity, the time, to contemplate and reflect. Within wilderness the demands for action might come more naturally from the organic rhythms of nature. For example, to eat when hungry, to sleep when tired, and to calibrate the day by the warmth of the sun might represent timelessness. Solitude in wilderness is an important aspect of people's enjoyment of the tranquility and naturalness of the environment. It is one of the legally defined and required characteristics of wilderness. Hammitt and Madden (1989) in an effort to measure privacy and solitude in wilderness, found that the "tranquility and peacefulness of the remote environment, and an environment free of human generated noises to be the . . most important" ( $p$. 296). The basic theme of oneness indicates that wilderness allows a unique opportunity to establish or re-establish close relationships with nature. In wilderness, humans are perhaps most free to see themselves as connected to and dependent upon the rhythms of nature. Wilderness purportedly fosters harmony and immersion within nature. Feelings of humility could be expected in wilderness, given the complexity, beauty, sometimes horror, and often grand scale of essentially untrammeled nature. Feelings of insignificance, lack of superiority, and awe could be expected, given the lack of control visitors have over the wilderness environment. It is a powerful message of wilderness that humans are but a small part of a much larger community of beings, each sacred in its own right. An ethic of care reflects perhaps one of the greatest impacts any wilderness experience could providea questioning, extension or alteration of an ethical stance. The wilderness visit may induce profound changes in people's relationship to nature and value systems. Many of the wilderness writers saw the logical extension of admiration and enjoyment of wild places to be an ethical stance that prioritized action to preserve nature.

\section{Measuring On-Site Leisure Experiences in Wilderness}

Development of items/scales to measure mode of experience and feelings of connection to wilderness was guided by the goal of adequately representing the domains of these constructs, but at the same time recognizing any measures must be brief enough to be completed multiple times during the lived wilderness experience. When possible, items previously found valid and reliable by other researchers were employed in existing or slightly modified form. When no such existing items/scales were available, we developed, 
tested, assessed validity and reliability, modified as necessary, and retested items among university students and a sample of canoeists at Juniper Prairie Wilderness in Florida.

For example, for mode of experience scales, we used or adapted measures of "focus on self-introspection" and "focus on others-degree of socialness" developed by Fenigstein, Scheir, and Buss (1975) and Samdahl and Kleiber (1989). For "focus on task-task orientation" and "focus on affect-emotional intensity," we adapted and supplemented items from Baldwin and Tinsley (1988). "Focus on nature-environmental awareness" items are our own. Items measuring aspects of a wilderness experience are also largely our own. We did lean heavily on Hammitt and Madden (1989) in the development of solitude items.

Through this means, three to six items measuring each of the study's 11 constructs (i.e., leisure states of mind) were presented to study respondents on a two-sided cover stock page. Respondents indicated how much they were feeling each construct on a nine-point "not at all" to "very much" scale at the times they were queried during the on-site experience.

\section{Date Collection Procedures}

The Experience Sampling Method (Csikszentmihalyi, Larson, and Prescott 1977) was used to sample moments in time throughout the subjects' wilderness experience as a means of capturing a record of the experience unfolding in real time. The Experience Sampling Method (ESM) consists of asking individuals to carry electronic beepers which signal pre-programmed random points of time at which subjects report or rate the immediate experience by filling out a questionnaire. The general purpose is to "study the subjective experience of persons interacting with natural environments" (Csikszentmihalyi and Larson 1987, p. 526). It has frequently been used to study flow, perceived freedom, and intrinsic motivation, particularly as found in leisure (Csikszentmihalyi and Rathunde 1993; Graef, Csikszentmihalyi, and Gianinno 1983; and Samdahl 1988, 1992). In general, the ESM appears to have both philosophical and practical advantages when measuring immediate experiences, with well-described reliability and the validity necessary for its widespread application (Csikszentmihalyi and Larson 1987).

Each study participant was given a packet of surveys and an electronic beeper programmed to sound at random times during the length of the trip. For example, the average length of stay of day visitors was 5 hours and 20 minutes, and they were beeped at a randomly selected point of time within each 1/2-hour block of time (or typically about three times during their visit). The average length of stay of overnight visitors was 50 hours and 30 minutes (a two- to three-day trip), and they were beeped once each morning between 8:00 a.m. and 12:30 p.m. and once in the afternoon or early evening between 12:30 p.m. and 6:30 p.m. (or an average of four to five times across the course of their trip). The research technician met sampled groups at the 
exit point from their trip to collect survey instruments. Respondents were not paid for their involvement, and participation was entirely voluntary at any point in time.

All 62 groups completed at least one, and up to nine, ESM questionnaires during the course of their wilderness visit.

\section{Data Analyses}

Three separate analyses were performed on study data: scale confirmation (reliability and factor analyses), analysis of variance (repeated measures analysis), and planned comparisons (Helmert comparisons).

Final items used to measure the five modes of environmental experience and the six aspects of the wilderness experience are shown in Tables 1 and 2. Items were deleted if the item-total correlation and communality was less than 0.4 , and if in doing so, coefficient alpha and variance explained increased significantly. We then submitted our mode of experience items and

TABLE 1

Factor Analysis of Mode of Environmental Experience Items $(n=221)$

\begin{tabular}{|c|c|c|c|c|}
\hline \multirow[b]{2}{*}{ Item } & \multicolumn{4}{|c|}{ Factor } \\
\hline & 1 & 2 & 3 & 4 \\
\hline \multicolumn{5}{|l|}{ Focus on self/Introspection } \\
\hline How much were you focusing on your own thoughts & .67 & & & \\
\hline I was reflecting on myself a lot & .81 & & & \\
\hline I was thinking about my place in the world & .75 & & & \\
\hline \multicolumn{5}{|l|}{ Focus on others/Social Acceptance } \\
\hline I feel a special closeness with others in my group & & & & .81 \\
\hline Other group members were accepting me for who I am & & & & .83 \\
\hline \multicolumn{5}{|l|}{ Focus on task/Task Orientation } \\
\hline How much were you focusing on the task you were carrying out & & .83 & & \\
\hline I was focusing on achieving the next goal of my trip & & .79 & & \\
\hline I was concentrating on doing my activity right & & .84 & & \\
\hline \multicolumn{5}{|l|}{ Focus on environment/Environmental awareness } \\
\hline $\begin{array}{l}\text { How much were you focusing on the natural environment } \\
\text { around you }\end{array}$ & & & .76 & \\
\hline I notice the little things of nature more than before & & & .80 & \\
\hline \multicolumn{5}{|l|}{ Focus on emotions/Emotional intensity } \\
\hline How much were you focusing on your feelings and emotions & .76 & & & \\
\hline I was very aware of my feelings & .78 & & & \\
\hline The feelings I was experiencing were more intense than usual & .47 & & .62 & \\
\hline Percentage of variance explained by factor & 29.7 & 15.8 & 12.7 & 8.0 \\
\hline
\end{tabular}

Note. Only factor weights over .40 are displayed. 
$T A B L E 2$

Factor Analysis of Mode of Wilderness Experience Items $(n=221)$

\begin{tabular}{|c|c|c|c|c|}
\hline \multirow[b]{2}{*}{ Item } & \multicolumn{4}{|c|}{ Factor } \\
\hline & 1 & 2 & 3 & 4 \\
\hline \multicolumn{5}{|l|}{ Oneness } \\
\hline I feel a part of wild nature & .66 & & & \\
\hline I was feeling a special closeness with nature & .73 & & & \\
\hline I was feeling totally immersed in nature & .75 & & & \\
\hline \multicolumn{5}{|l|}{ Timelessness } \\
\hline I care what time it is & & & .84 & \\
\hline I was worrying about the time & & & .88 & \\
\hline I care what time it is when I eat & & & .62 & \\
\hline \multicolumn{5}{|l|}{ Primitiveness } \\
\hline I felt I was living like a pioneer & .64 & & & \\
\hline I feel the simplicity of life on this trip & .61 & & & \\
\hline I felt that life was simple & .65 & & & \\
\hline I felt connected with times long ago & .69 & & & \\
\hline I was feeling the heartbeat of the earth & .73 & & & \\
\hline \multicolumn{5}{|l|}{ Humility } \\
\hline I was in awe of nature's creation & .78 & & & \\
\hline I felt humbled by all of nature around me & .72 & & & \\
\hline I was feeling insignificant in the glory of nature & .57 & & & \\
\hline \multicolumn{5}{|l|}{ Solitude } \\
\hline The environment seems free of human-made noise & & & & .44 \\
\hline I feel the tranquility and peacefulness of this place & & & & .78 \\
\hline I felt the silence of the environment & & & & .89 \\
\hline \multicolumn{5}{|l|}{ Care } \\
\hline I feel I want to care for this place & & .73 & & \\
\hline I want to behave properly towards this place & & .79 & & \\
\hline Percentage of variance explained by factor & 34.8 & 10.9 & 7.1 & 5.2 \\
\hline
\end{tabular}

our wilderness experience items to exploratory factor analysis to see if our hypothesized scales measured distinct constructs. A total of 221 surveys from 62 subjects were used in these analyses.

Repeated measures analysis of variance was then used to examine whether phase of the wilderness experience is a significant explanatory variable for the two dependent constructs, modes of environmental experience and aspects of wilderness experience. Three phases of the wilderness experience were defined using elapsed time relative to the total length of the wilderness visit. That is, responses were considered to represent the entry phase and the exit phase if they were from a questionnaire completed during the first $25 \%$ and last $25 \%$ of the visit, respectively. Questionnaires completed during the middle $50 \%$ of the visit were aggregated into the immersion 
phase. ${ }^{1}$ If visitors completed more than one questionnaire in any one of the three phases, the scale scores were averaged for that phase. Because subjects were measured on more than one occasion, a repeated measures design was used. Such designs are particularly powerful in that error variance is substantially reduced, and fewer subjects are needed than for other designs. In this study, a doubly multivariate repeated measures MANOVA was used, since there was more than one dependent measure being analyzed across multiple points in time (Norusis, 1994). Both univariate and multivariate repeated measures analysis of variance were used to examine the explanatory role of phase of the experience. That is, each of the dependent measures was examined by a univariate repeated measures design, and then the two sets of dependent variables (modes of environmental experience and aspects of wilderness experience) were examined with multivariate repeated measure tests. Univariate and multivariate tests discern different treatment effects. Multivariate tests may mask some of the univariate effects if two dependent variables in effect cancel one another out. There is not one universally accepted test statistic for the multivariate analysis. The most widely known (and utilized in this study) is Wilk's lambda, which compares the generalized variance of the within and total sum of squares and cross product matrices (Stevens, 1992).

Repeated measures analyses are particularly sensitive to missing data and for this reason a subset of visitors was selected. To be included, subjects must have completed at least 3 questionnaires during the wilderness experience, and at least one during each of the first $25 \%$, middle $50 \%$, and last $25 \%$ of the trip. In addition, all of the items of the modes of experience or all of the wilderness experience scale items must have been completed. For the scales measuring aspects of wilderness experience, 23 subjects completed all items (110 questionnaires). For the modes of environmental experience, 20 subjects completed all items (94 questionnaires). In filtering respondents in this manner, all but one of the day visitors (who stayed in the wilderness for nearly 12 hours) were excluded from subsequent analysis.

The final analyses were planned multivariate comparisons between specific combinations of phases of the experience. Equivalent to post-hoc contrasts such as Tukey's HSD, when an overall significant difference is found between the groups, multivariate comparisons (Helmert contrasts) are used to examine which groups are different. Note that Helmert contrasts are a component of the multivariate analysis. Thus, it is appropriate to carry out Helmert planned comparisons if the multivariate test shows a significant difference, even if a univariate test showed no significant difference for a particular dependent variable within the multivariate test.

\footnotetext{
${ }^{1}$ The assignment of a $1 / 4,1 / 2$, and $1 / 4$ split of trip time into entry, immersion, and exit phases was somewhat arbitrary. The entry and exit phases may indeed be shorter, because we found a similar pattern of responses when we defined the phases as the first $1 / 6^{\text {th }}$, the middle $2 / 3$ rds, and last $1 / 6^{\text {th }}$ of the trip.
} 
Results

\section{Research Question 1}

Factor analyses, reliability analyses, and an examination of the importance levels of mode of environmental experience and wilderness experience scales were completed to identify the leisure states of mind during a wilderness engagement. Table 1 gives a factor analysis (varimax rotation) of the 13 items used to construct five modes of environmental experience scales. Focus on self/introspection factored out as the first factor, with each of the three items carrying a weight of 0.6 or higher. Two of the three projected emotional intensity items also correlated with these self/introspection items, as might be expected given the internal focus of both groups of questions. The other emotional intensity item factored with the items on environment (factor 3), perhaps indicating the emotional impact of the wilderness environment. Otherwise, the factor analysis confirmed the suggested modes of environmental experience. Thus, four environmental experience scales were used in subsequent analyses.

Table 2 shows a similar factor analysis for the six wilderness experience scales, which were asked as a separate block on the experience sampling questionnaire. The three solitude items, the two care items, and three timelessness items all factored as separate dimensions of the wilderness experience, as anticipated. However, oneness, humility, and primitiveness all factored together, reflecting the interrelated nature of these concepts. Four wilderness experience scales were therefore used in further analyses.

Tables 3 and 4 show the final items and reliability analyses of the four modes of environmental experience and the four aspects of the wilderness experience. All eight scales had coefficient alpha reliabilities above 0.60 . These reliability levels were judged to be adequate. The overall mean scores of eight scales, viewed as descriptors of the leisure experience in wilderness, varied in importance on wilderness feelings from a low of 4.5 (on a one to nine scale) on oneness/primitiveness/humility to 7.7 on timelessness and care (Table 3), and from a low of 3.1 on introspection to a high of 6.1 on social acceptance on mode of environmental experience scales (Table 4).

\section{Research Questions 2 and 3}

Tables 5 and 6 indicate a statistically significant difference in modes of environmental experience (Wilk's lambda $=0.59, p<0.012$ ) and in aspect of the wilderness experience (Wilk's lambda $=0.58, p<0.003$ ) by trip phase.

Tables 7 and 8 show the mean scores for each mode of environmental experience and wilderness experience scale for the three hypothesized trip phases. In general, scores on timelessness and feelings of care were higher than for feelings of solitude and humility/primitiveness/oneness. Respondents also had a higher average focus on others in the group and on the environment than on task or on self.

Tables 7 and 8 also list the univariate statistics of a repeated measures analysis of variance for effect of phase on response to each scale. Table 7 
TABLE 3

Reliability Analysis of Aspects of Environmental Experience Scales $(n=221)$

\begin{tabular}{|c|c|c|c|c|c|}
\hline \multirow[b]{2}{*}{ Item } & \multicolumn{5}{|c|}{ Scale } \\
\hline & Mean & $\begin{array}{l}\text { Std. } \\
\text { Dev. }\end{array}$ & $\begin{array}{c}\text { Item-total } \\
\text { Correlation }\end{array}$ & $\begin{array}{l}\text { Variance } \\
\text { If Deleted }\end{array}$ & $\begin{array}{l}\text { Alpha } \\
\text { If Deleted }\end{array}$ \\
\hline $\begin{array}{l}\text { Focus on self } / \text { Introspection } \\
\qquad(\text { Alpha }=0.83, \text { total variance }=103.3)\end{array}$ & 3.1 & & & & \\
\hline How much were you focusing on your own thoughts & 3.0 & 2.6 & 0.52 & 73.6 & 0.81 \\
\hline I was reflecting on myself a lot & 2.5 & 2.4 & 0.69 & 70.1 & 0.78 \\
\hline I was thinking about my place in the world & 2.6 & 2.8 & 0.61 & 67.9 & 0.80 \\
\hline $\begin{array}{l}\text { How much were you focusing on your feelings and } \\
\text { emotions }\end{array}$ & 3.5 & 2.7 & 0.63 & 67.6 & 0.79 \\
\hline I was very aware of my feelings & 3.9 & 2.7 & 0.67 & 65.7 & 0.78 \\
\hline $\begin{array}{l}\text { Focus on others } / \text { Social Acceptance } \\
\qquad(\text { Alpha }=0.63, \text { total variance }=19.9)\end{array}$ & 6.1 & & & & \\
\hline I feel a special closeness with others in my group & 5.3 & 2.6 & 0.46 & 6.7 & - \\
\hline Other group members were accepting me for who I am & 6.9 & 2.6 & 0.46 & 7.0 & - \\
\hline $\begin{array}{l}\text { Focus on task } / \text { Task Orientation } \\
\qquad(\text { Alpha }=0.77, \text { total variance }=56.4)\end{array}$ & 4.3 & & & & \\
\hline $\begin{array}{l}\text { How much were you focusing on the task you were } \\
\text { carrying out }\end{array}$ & 5.4 & 3.0 & 0.59 & 56.4 & 0.71 \\
\hline I was focusing on achieving the next goal of my trip & 2.9 & 3.0 & 0.57 & 28.2 & 0.72 \\
\hline I was concentrating on doing my activity right & 4.6 & 3.0 & 0.64 & 28.9 & 0.64 \\
\hline $\begin{array}{l}\text { Focus on enviromment } / \text { Environmental awareness } \\
\quad(\text { Alpha }=0.69, \text { total variance }=36.9)\end{array}$ & 5.2 & & & & \\
\hline $\begin{array}{l}\text { How much were you focusing on the natural } \\
\text { environment around you }\end{array}$ & 6.3 & 2.5 & 0.38 & 21.5 & 0.63 \\
\hline I notice the little things of nature more than before & 5.3 & 2.5 & 0.59 & 17.9 & 0.48 \\
\hline $\begin{array}{l}\text { The feelings I was experiencing were more intense } \\
\text { than usual }\end{array}$ & 4.1 & 2.7 & 0.54 & 17.4 & 0.55 \\
\hline
\end{tabular}

indicates that two of the four wilderness experience scales (i.e., the primitiveness/oneness/humility $(p=.0001)$ and the care $(p=.03)$ variables) differed significantly across phases. Examination of the means suggests that importance of these wilderness aspects increase from entry to immersion and from immersion to exit phase. One mode of environmental experience changed across phase: focus on the environment increased from entry to the immersion/exit phase $(p=0.04)$.

The Helmert contrasts of the multivariate analyses reported in Table 9 provide a somewhat different perspective. Differences in wilderness experiences and in mode of environmental experiences were most frequent between entry and exit phases of the trip. Significant increases in feelings of humility/primitiveness/oneness and of care, and in focus on self and on environmental awareness, occurred from the entry to the exit phases. The only significant increase in any of the study's measures that occurred between entry and immersion was for humility/primitiveness/oneness, although focus on the environment came close to achieving significance. In contrast, feelings of closeness/social acceptance by other group members was signif- 
TABLE 4

Reliability Analysis of Aspects of Wilderness Experience Scales $(n=221)$

\begin{tabular}{|c|c|c|c|c|c|}
\hline \multirow[b]{2}{*}{ Item } & \multicolumn{5}{|c|}{ Scale } \\
\hline & Mean & $\begin{array}{l}\text { Std. } \\
\text { Dev. }\end{array}$ & $\begin{array}{l}\text { Item-total } \\
\text { Correlation }\end{array}$ & $\begin{array}{l}\text { Variance } \\
\text { If Deleted }\end{array}$ & $\begin{array}{l}\text { Alpha } \\
\text { If Deleted }\end{array}$ \\
\hline $\begin{array}{l}\text { Oneness } / \text { Primitiveness } / \text { Humility } \\
\qquad(\text { Alpha }=0.91, \text { total variance }=416.4)\end{array}$ & 4.5 & & & & \\
\hline I feel a part of wild nature & 4.7 & 2.6 & 0.63 & 348.0 & 0.90 \\
\hline I was feeling a special closeness with nature & 6.1 & 2.5 & 0.72 & 345.1 & 0.89 \\
\hline I was feeling totally immersed in nature & 5.6 & 2.4 & 0.76 & 343.9 & 0.89 \\
\hline I felt I was living like a pioneer & 2.2 & 2.2 & 0.51 & 366.9 & 0.90 \\
\hline I feel the simplicity of life on this trip & 4.5 & 2.6 & 0.67 & 349.1 & 0.90 \\
\hline I felt that life was simple & 3.3 & 2.7 & 0.64 & 348.5 & 0.90 \\
\hline I felt connected with times long ago & 3.5 & 2.8 & 0.64 & 344.0 & 0.90 \\
\hline I was feeling the heartbeat of the earth & 3.5 & 2.8 & 0.66 & 341.8 & 0.90 \\
\hline I was in awe of nature's creation & 5.9 & 2.5 & 0.68 & 345.9 & 0.90 \\
\hline I felt humbled by all of nature around me & 5.2 & 2.7 & 0.70 & 339.1 & 0.90 \\
\hline I was feeling insignificant in the glory of nature & 4.0 & 2.7 & 0.59 & 348.3 & 0.90 \\
\hline $\begin{array}{l}\text { Timelessness } \\
\qquad(\text { Alpha }=0.72, \text { total variance }=26.1)\end{array}$ & 7.7 & & & & \\
\hline I care what time it is & 7.7 & 2.0 & 0.62 & 13.1 & 0.53 \\
\hline I was worrying about the time & 7.9 & 2.1 & 0.68 & 11.6 & 0.44 \\
\hline I care what time it is when I eat & 7.5 & 2.2 & 0.34 & 15.1 & 0.86 \\
\hline $\begin{array}{l}\text { Solitude } \\
\qquad(\text { Alpha }=0.74, \text { total variance }=42.8)\end{array}$ & 5.8 & & & & \\
\hline $\begin{array}{l}\text { The environment seems free of human-made } \\
\text { noise }\end{array}$ & 6.9 & 2.2 & 0.52 & 26.5 & 0.77 \\
\hline $\begin{array}{l}\text { I feel the tranquility and peacefulness of this } \\
\text { place }\end{array}$ & 5.3 & 2.8 & 0.70 & 18.2 & 0.56 \\
\hline I felt the silence of the environment & 5.2 & 2.9 & 0.61 & 19.1 & 0.68 \\
\hline $\begin{array}{l}\text { Care } \\
\qquad(\text { Alpha }=0.67, \text { total variance }=12.8)\end{array}$ & 7.7 & & & & \\
\hline I feel I want to care for this place & 7.3 & 2.3 & 0.52 & 3.2 & - \\
\hline I want to behave properly towards this place & 8.0 & 1.8 & 0.52 & 5.3 & \\
\hline
\end{tabular}

TABLE 5

Multivariate Repeated Measures Analysis of the Relationship Between Trip Phase and Scores on Modes of Environmental Experience Scales

\begin{tabular}{lccccc}
\hline $\begin{array}{l}\text { Multivariate Tests of Significance } \\
\quad(S=1, M=.5, N=19.5)\end{array}$ & Value & $\begin{array}{c}\text { Approx. } \\
\text { F }\end{array}$ & $\begin{array}{c}\text { Hypothesis } \\
\text { DF }\end{array}$ & $\begin{array}{c}\text { Error } \\
\text { DF }\end{array}$ & $\begin{array}{c}\text { Significance } \\
\text { of F }\end{array}$ \\
\hline Wilk's lambda & 0.59 & 2.68 & 8 & 70 & 0.012 \\
Pillais & 0.46 & 2.72 & 8 & 72 & 0.014 \\
Hotellings & 0.62 & 2.63 & 8 & 68 & 0.014 \\
Roys & 0.29 & & & & \\
\hline
\end{tabular}




\section{TABLE 6}

Multivariate Repeated Measures Analysis of the Relationship Between Trip Phase and Scores on Aspects of Wilderness Experience Scales

\begin{tabular}{lccccc}
\hline $\begin{array}{l}\text { Multivariate Tests of Significance } \\
(S=1, M=.5, N=19.5)\end{array}$ & Value & $\begin{array}{c}\text { Approx. } \\
\text { F }\end{array}$ & $\begin{array}{c}\text { Hypothesis } \\
\text { DF }\end{array}$ & $\begin{array}{c}\text { Error } \\
\text { DF }\end{array}$ & $\begin{array}{c}\text { Significance } \\
\text { of F }\end{array}$ \\
\hline Wilk's lambda & 0.58 & 3.18 & 8 & 82 & 0.003 \\
Pillais & 0.42 & 2.78 & 8 & 84 & 0.009 \\
Hotellings & 0.71 & 3.57 & 8 & 80 & 0.001 \\
Roys & 0.42 & & & & \\
\hline
\end{tabular}

TABLE 7

Univariate Repeated Measures Analysis of the Relationship Between Trip Phase and Aspects of Wilderness Experience Scales $(n=20)$

\begin{tabular}{lcccccc}
\hline \multirow{2}{*}{\multicolumn{1}{c}{ Scale }} & \multicolumn{3}{c}{ Phase Means } & & Univariate $F$ & Significance \\
\cline { 2 - 5 } & Entry & Immersion & Exit & with (2.44) d.f. & of \\
\hline Humility/Primitiveness/Oneness & 4.4 & 4.9 & 5.3 & 8.82 & 0.001 \\
Timelessness & 7.9 & 7.8 & 7.7 & 0.25 & 0.78 \\
Solitude & 5.7 & 6.1 & 6.3 & 1.65 & 0.20 \\
Care & 7.5 & 7.8 & 8.0 & 3.79 & 0.03 \\
\hline Mean no. of questionnaires/respondent & 1.5 & 1.8 & 1.5 & & \\
\hline
\end{tabular}

TABLE 8

Univariate Repeated Measures Analysis of the Relationship Between Trip Phase and Modes of Environmental Experience Scales $(n=23)$

\begin{tabular}{lcccccc}
\hline \multirow{2}{*}{ Scale } & \multicolumn{3}{c}{ Phase Means } & & Univariate $\mathbf{F}$ & $\begin{array}{c}\text { Significance } \\
\text { of } \mathbf{F}\end{array}$ \\
\cline { 2 - 5 } & Entry & Immersion & Exit & with (2.38) d.f. & 0.12 \\
\hline Self/Introspection & 2.9 & 3.3 & 3.6 & 2.21 & 0.19 \\
Others/Social acceptance & 6.2 & 5.5 & 6.3 & 4.40 & 0.61 \\
Task orientation & 3.9 & 4.3 & 4.3 & 0.48 & 0.04 \\
Environmental awareness & 4.7 & 5.3 & 5.3 & 3.61 & \\
\hline Mean no. of questionnaires/respondent & 1.6 & 1.9 & 1.5 & & \\
\hline
\end{tabular}


TABLE 9

Planned Comparisons Between Trip Phases and Aspects of Wilderness Experience and Modes of Environmental Experience Using Helmert Contrasts

\begin{tabular}{|c|c|c|c|c|c|c|c|c|c|}
\hline \multirow[b]{2}{*}{ Scale } & \multicolumn{3}{|c|}{ Phase Means } & \multicolumn{2}{|c|}{ Entry vs. Exit } & \multicolumn{2}{|c|}{$\begin{array}{l}\text { Entry vs. } \\
\text { Immersion }\end{array}$} & \multicolumn{2}{|c|}{$\begin{array}{c}\text { Immersion vs. } \\
\text { Exit }\end{array}$} \\
\hline & Entry & Immersion & Exit & $\mathbf{F}$ & Signif. & $\mathbf{F}$ & Signif. & $\mathrm{F}$ & Signif. \\
\hline Humility/Primitiveness/Oneness & 4.4 & 4.9 & 5.3 & 18.87 & 0.00 & 7.39 & 0.01 & 1.92 & 0.18 \\
\hline Timelessness & 7.9 & 7.8 & 7.7 & 0.76 & 0.39 & 0.12 & 0.73 & 0.09 & 0.77 \\
\hline Solitude & 5.7 & 6.1 & 6.3 & 2.32 & 0.14 & 2.04 & 0.16 & 0.37 & 0.55 \\
\hline Care & 7.5 & 7.8 & 8.0 & 6.21 & 0.02 & 1.38 & 0.25 & 5.16 & 0.33 \\
\hline Self/Introspection & 2.9 & 3.3 & 3.6 & 4.33 & 0.05 & 1.78 & 0.20 & 0.64 & 0.43 \\
\hline Others/Social acceptance & 6.2 & 5.5 & 6.3 & 0.14 & 0.70 & 4.46 & 0.05 & 7.09 & 0.02 \\
\hline Task orientation & 3.9 & 4.3 & 4.3 & 0.66 & 0.42 & 0.71 & 0.41 & 0.00 & 0.99 \\
\hline Environmental awareness & 4.7 & 5.3 & 5.3 & 5.69 & 0.03 & 2.65 & 0.12 & 1.19 & 0.29 \\
\hline
\end{tabular}


icantly lower during the immersion than either of the entry or the exit phases. No differences were found across trip phases for feelings of timelessness or solitude, or for focus on task.

\section{Discussion}

As expected, wilderness experiences involved multiple states of mind, and both the mode of experiencing wilderness and feelings of connection to fundamental qualities of wilderness were dynamic across time during a wilderness visit. These changes had a multi-phasic pattern. However, the nature of the wilderness experience and how it changed across time was not always the way we had expected. For example, based on the writings of wilderness philosophers that shaped the creation of the National Wilderness Preservation System, we felt that primitiveness (i.e., simple living, living like a pioneer, living without modern technological conveniences), oneness (i.e., feeling connected to nature, immersed in nature, part of nature), and humility (i.e., feelings of awe and insignificance in the glory of nature) were distinct aspects of the wilderness ideal. But for the group of wilderness visitors studied here, this was not the case. All three constructs collapsed into one. Today's wilderness visitors at Okefenokee may indeed not construct their wilderness experience with the distinctions suggested by the writings of the wilderness philosophers. Another possibility is that our scales, being largely untested before the study and containing fewer items by necessity of multiple applications in a field setting, were not precise enough to identify subtle differences in wilderness experiences. Only additional scale development and testing and/or the use of multiple measurement strategies will permit more definitive conclusions on the complexity of this aspect of leisure experiences in wilderness.

Similar conclusions might be drawn about focus on emotions/emotional intensity as a mode of nature-person transactions in wilderness. As stated earlier in this paper, emotional involvement is a significant component of leisure experiences. The writings of Henry David Thoreau, John Muir, and Sigurd Olson cited above also suggest the strong emotions evoked by wilderness. Hull et. al. (1992) demonstrated the importance of mood and mood changes to understanding the overall wilderness experience pattern. Yet in this study, projected focus-on-emotion items loaded with focus on self/introspection or on focus on environment items. Emotional responses at Okefenokee apparently did not overwhelm attention to the environment or attention to one's own thoughts/one's place in the environment. This response may be common to most wilderness areas; it may be unique to Okefenokee, or it may reflect problems in measurement.

The relative importance given to various modes of experiencing the wilderness and feelings about idealized aspects of wilderness was also somewhat different from what might have been expected based on the writings of the wilderness philosophers. Marshall encountered wilderness on prodigious hikes and mountain climbs, and his writing extols the benefit of phys- 
ical activity and challenge. Leopold, at least early in his literacy career, writes of the joy and value of lengthy horse-packing trips into wilderness. Thoreau and Muir studied the environment with great intensity of their excursions into wild places. Muir meditated in wilderness and crossed over the barrier separating humans from wild nature. In such times of transcendence Muir felt deeply connected to nature, and felt awe and humility. Thoreau went to the woods for simple living, and felt a different sort of awe and humility on the dark flanks of Mount Katahdin.

But for the most part, Okefenokee visitors did not experience their wilderness quite this way, nor did they have these kinds of very intense feelings. Their highest focus was on other members of their group, followed by midlevel focus given to the environment and to task. Focus on self/introspection was, on average low across time and across individuals. Feelings of oneness/ primitiveness/humility, apparently so important to the wilderness philosophers, was only of mid-level importance to Okefenokee users.

A variety of reasons can be given to explain these differences. The wilderness writers were literary giants. They were able to express their feelings with great skill. Our study respondents checked boxes in response to scaled items. Our study respondents also reported their focus of attention and feelings in real time (i.e., at the moment of the event). The wilderness writers typically wrote of their experiences after, sometimes long after, their encounter with nature. They had more time to "construct" the meanings of their experience. Another possibility is that the wilderness philosophers were writing of transcendent experiences in wilderness. Our respondents may have been reporting rather ordinary experiences in a particular wilderness. Indeed, one of the advantages of the experience sampling approach is that it is able to obtain valid and reliable measures of ordinary events of people's lives usually in an everyday context. Particular aspects of the Okefenokee environment might also have strongly shaped experiences reported. For example, the mid-range solitude scores and the high-end timelessness scores might have been even higher had the Okefenokee trips been longer with fewer encounters with other recreationists. Finally, wilderness visitors today could construct their experiences quite differently than in the past. Wilderness is after all a cultural construct that evolves across time and context. Some work in Australia reports findings similar to our own giving support to the specific effects of context. Scherl (1990), for instance, found that participants on an Outward Bound trip in wilderness most frequently reported their activities in their diaries, followed by reference to self, the social setting, and only then to the physical setting and to emotional state. McIntyre (1998) employed an experience sampling method among wilderness visitors and found focus on social acceptance by group and on task to be much more prevalent than focus on the environment or on self. Feelings of timelessness and care for the place were high, solitude was mid-level, and oneness and primitiveness were low. 


\section{Wilderness as Multi-phasic}

Overall, multivariate analyses demonstrated that scales measuring mode of environmental experience and scales measuring different aspects of wilderness vary significantly across phases of the experience. Of the eight unique measures of the lived experience in wilderness included in this study, univariate repeated measures analysis indicated that three varied across entry, immersion, and/or exit phases. Helmert comparisons (within multivariate repeated measures analyses) suggested that five of the eight measures varied across phases. The three that didn't vary were focus on task and feelings of timelessness and solitude. One might expect all three of these experience measures to be highest during the immersion phase. During the entry and exit phases the wilderness participant would typically be on the move, i.e., walking or paddling to get into or get out of the wilderness. During the middle part of the trip, the participant would most likely be at a destination deep inside the wilderness; there they would less likely see or hear other people, and they would less likely be concerned about time. The fact that this didn't happen likely reflects the nature of the Okefenokee trip. The typical Okefenokee trip is not very long. Visitors can reach all of the overnight camping platforms in a day's paddle, and they cannot spend any more than one night on a given platform before moving on. Thus, wilderness visitors are almost always moving, usually they are going in or coming out, and visitors, be they overnight or day users, can reach virtually any spot on the canoe routes in the wilderness in a day's paddle.

We had expected that feelings of closeness/acceptance by one's group would build during the trip, but would increase the most from entry to immersion phases. During the entry phase, group members would struggle to become a cohesive group. During periods of lesser activity and more time during immersion, group bonding would likely occur. But this didn't happen. Indeed, group cohesion was lowest during the immersion phase of the trip. Perhaps, the immersion phase was of the most part spent paddling, and during this period of most remoteness in the wilderness (and the farthest yet to go to return to civilization), group members may have felt the most pressure from their canoe partners and group members to perform adequately.

On those experience dimensions which are arguably the most dependent on personal connection with the wilderness environment, scores changed across phases of the experience in ways that made intuitive sense. Focus on the environment gradually increased across the trip phases, almost reaching statistical significance during immersion and reaching such significance during the exit phase. Focus on self/introspection, while low throughout, gradually increased to reach a significant level of gain by the exit phase. We had expected this significant change to occur more quickly, but the failure of task orientation to drop during the immersion phase likely slowed the development of this orientation. Feelings of care for the environment 
showed the same pattern of change as did the introspective mode of interacting with the environment, probably for similar reasons. Finally, feelings of primitiveness, oneness, and humility, apparently less constrained and perhaps even enhanced by focus on task, grew significantly across all trip phases.

\section{Some Precautionary Notes}

The Experience Sampling Method (ESM) was used in this study to obtain real time measure of significant aspects of the leisure experience in wilderness. Preprogrammed beepers sounded at random times during the trip, and at these moments study participants completed a short checklist of feelings and attentional states. This methodology has several advantages for measuring the dynamic nature of leisure experiences, and these have been cited above. But as with any methodology, the ESM approach has weaknesses, and these may be especially onerous in a wilderness setting. We thus end our discussion with some cautions.

First, the introduction of beeper technology into the wilderness setting is antithetical to the ideal of wilderness as free from modern technology. While Okefenokee Wilderness has motor boats, aluminum canoes, camping platforms, and vault toilets/porta potties, and some users there probably carry in such modern technology as cell/mobile telephones, GPS units, and other portable electronic devices, the introduction of additional technology for research purposes is still considered by some to be problematic (e.g., see Freimund and Borrie 1998, Borrie 2000).

Second, because of our concern about the intrusiveness of both the beeper technology and the repeated measures of the experience in wilderness, we limited the number of sampling times on any given individual's trip. But this leads to the difficult question of whether we would have gotten different results had we gained a greater coverage of the range of events on the trip. As examples, we wonder if we adequately sampled the camping experience on the platform in the swamp, or if we adequately covered such peak moments as spotting an alligator or viewing the swamp's night sky with its billion stars. It is difficult to know when sampling levels become adequate.

Third, the repeated measures design requires an effort by respondents multiple times to complete the inventory checklist. Wilderness visitors are typically willing research subjects, and they were on this study. However, we still had many study participants who failed to complete all their survey iterations. Also the sensitivity of repeated measures analysis to missing responses caused us to throw out those individuals who completed a survey at each beep but who forgot to complete a single pertinent item on the survey. Because of these repeated measure requirements, the number of study participants in most of the analyses reported here dropped from 62 to the low 20s.

Finally, the issue of behavioral reactivity is concern for much visitor survey work, but particularly with methods such as ESM that set out to measure behavior, cognitions, and feelings multiple times across relatively short pe- 
riods. At Okefenokee, the very act of measuring focus of attention and feelings about wilderness multiple times may have primed or sensitized participants for subsequent responses. They may have paid more heed to their attentional states and to certain aspects of wilderness than they would have otherwise. On the other hand, measuring experiences in real time is almost certainly more accurate than surveys of the event long after it is over (Borrie, Roggenbuck \& Hull, 1998). Also, with this study, the respondents did not know when they would next be beeped. Finally, while there was some tendency in our study for the experience scores to increase across the duration of the trip, this was not always the case. Also, for most such increases there were conceptional or intuitive reasons to expect such increases.

\section{Conclusions and Recommendations}

This research, while it must be considered exploratory, suggests that the wilderness experience is dynamic, complex, and evolving. More importantly, there is evidence that the experience is multi-phasic. After a period of time, a time which we call the entry phase, wilderness visitors tended to attune more to certain aspects of the wilderness environment and to feel greater connection to some core wilderness values. Contrary to expectations, these changes tended to build throughout the experience, and not decline during the exit phase of the trip. But much more research is necessary before we can describe the dynamic lived experience of wilderness with greater certainty. We thus conclude with recommendations for further research.

We believe that innovative measurement instruments/protocol were necessary to obtain real-time measures of the dynamic and meaningful aspects of a leisure experience in wilderness. Given this, we selected the ESM approach, and attempted to sample random moments in time during the lived experience. But special or peak moments/places/times might be more instructive than the ebb and flow of ordinary moments. Researchers should make an effort to identify and sample these times and events. There may be a pattern across time into the trip and/or of special places of transition that most shape the lived experience and also define boundaries of significant trip phases.

In line with this, we emphasized and found some support for time into the on-site trip relative to its beginning and its end that defined phases of the experiences. At the same time our identification of the phase boundaries was quite arbitrary. Future research should better consider the effects of trip length and of events/activities/places on length of trip phases and passage from one phase to another. McIntyre (1998) and McIntyre and Roggenbuck (1998) have begun to do this.

We believe the ESM has excellent potential to measure the dynamic and evolving nature of experiences in wilderness, and it should be further tested and refined. However, a mechanism other than the electronic beeper to call the response moment seems advisable. This seems possible, especially if it is learned that key times/places/events most shape the experience. At the same 
time as we call for additional testing of the ESM, we recognize the need for multiple methods/technologies to measure the complexity of leisure experiences in general, and in wilderness in particular. Stewart (1998) recognized that leisure experiences are emergent, and are created in part as personal stories with temporal and spatial qualities. We doubt that the ESM approach adequately taps the emergent story, the story that begins to develop on-site but that almost certainly continues off-site. We received hints that our respondents were carrying their experience through time with some of their highest scores during the exit phase of the trip. But we know little about how they were beginning to construct stories of their trip, how they were beginning and continuing to create meaning of their experience, and how they will embed their emergent stories in the context of their daily lives. For that, we need additional research and different research approaches.

\section{References}

Arnould, E. J. \& Price, L. L. (1993). River magic: Extraordinary experience and the extended service encounter. Journal of Consumer Research, 20, 2445.

Baldwin, K S. \& Tinsley, H. E. A. (1988). An investigation of the validity of Tinsley and Tinsley's (1986) theory of leisure experience. Joumal of Counseling Psychology, 35, 263-267.

Borrie, W. T. (2000). Impacts of technology on the meaning of wilderness. In A. E. Watson, G. H. Aplet, and J. C. Hendee, (Comps.), Personal, societal, and ecological values of wilderness: Sixth World Wilderness Congress proceedings on research, management, and allocation, Volume II. (pp. 8788). USDA Forest Service Proceedings RMRS-P-14. Ogden, UT: Rocky Mountain Research Station.

Borrie, W. T. Roggenbuck, J. W., \& Hull, R. B. NV (1998). The problem of verbal reports in recreation research: review, recommendations, and new directions. Tourism Analysis, 2, 175183.

Celsi, R. L., Rose, R. L., \& Leigh, T. W. (1993). An exploration of high-risk leisure consumption through skydiving. Journal of Consumer Research, 20, 1-23.

Clawson, M. \& Knetsch, J. L. (1966). Economics of Outdoor Recreation. Baltimore, MD: Johns Hopkins Press.

Csikszentmihalyi, M. (1975). Beyond boredom and anxiety. San Francisco, CA: Jossey-Bass.

Csikszentmihalyi, M., Larson, R., \& Prescott, S. (1977). The ecology of adolescent activity and experience. Journal of Personality, 50, 15-28.

Csikszentmihalyi, M. \& Larson, R. (1987). Validity and reliability of the Experience-Sampling Method. Journal of Nervous and Mental Disease, 175, 526-536.

Csikszentmihalyi, M. \& Rathunde, K. (1993). The measurement of flow in everyday life: toward a theory of emergent motivation. In J. E. Jacobs (ed.), Developmental Perspectives on Motivation: Volume 40 of the Nebraska Symposium on Motivation. (pp. 57-97). Lincoln, NE: University of Nebraska Press.

Fenigstein, A., Sheier, M. F., \& Buss, A. H. (1973). Public and private self-consciousness: Assessment and theory. Journal of Consulting and Clinical Psychology, 43, 522-527.

Freimund, W. A., \& Borrie, W. T. (1997). Wilderness in the $21^{\text {st }}$ Century-Are there technical solutions to our technical problems? International Joumal of Wilderness, 3, 21-23.

Graef, R., Csikszentmihalyi, M., \& Gianinno, S. M. (1983). Measuring intrinsic motivation in everyday life. Leisure Sciences, 2, 155-168.

Hammitt, W. E. \& Madden, M. A. (1989). Cognitive dimensions of wilderness privacy: a field test and further explanation. Leisure Sciences, 11, 293-301. 
Hull, R. B. IV, (1990). Emotion and leisure: causes and consequences. Joumal of Leisure Research, $22,55-67$.

Hull, R. B. IV \& Michael, S. E. (1995). Nature-based recreation, mood change, and stress reduction. Leisure Sciences, 17, 1-14.

Hull, R. B. IV, Michael, S. E., Walker, G., \& Roggenbuck, J. W. (1996). Ebb and flow of brief leisure experiences. Leisure Sciences, 18, 299-314.

Hull, R. B. IV, Stewart, W. P., \& Yi, Y. K. (1992). Experience patterns: Capturing the dynamic nature of a recreation experience. Journal of Leisure Research, 24, 240-252.

Ittelson, W. H. (1978). Environmental perception and urban experience. Environment and Behavior, 10, 193-213.

Ittelson, W. H., Franck, K A., \& O'Hanlon, T. J. (1978). The nature of environmental experience. In S. Wapner, B. Cohen, \& B. Kaplan (eds.), Experiencing the environment. (pp. 187206). New York: Plenum.

Kaplan, S., \& Talbot, J. F. (1983). Psychological benefits of a wilderness experience. In I. Altman, \& J. F. Wohlwill (eds.), Human behavior and environment: Vol. 6. Behavior and the natural environment. (pp. 163-203). New York: Plenum.

Klausner, S. Z. (1967). Sport Parachuting. In R. Slovenko and J. A. Knight (Eds.). Motivations in play, games, and sports. New York: Charles C. Thomas.

Lee, Y., Dattilo, J., \& Howard, D. (1994). The complex and dynamic nature of leisure experience. Joumal of Leisure Research, 26, 195-211.

Leopold. A. (1949). A Sand County Almanac and Sketches from Here E There. New York: Oxford University Press.

Mannell, R. C., Zuzanek, J., \& Larson, R. (1988). Leisure states and "flow experiences": testing perceived freedom and intrinsic motivation hypotheses. Joumal of Leisure Research, 20, 289304.

Marshall, R. (1930). The problem of wilderness. The Living Wilderness, 40, 31-35.

McIntyre, N. (1998). Person and environment transaction during brief wilderness trips: an exploration. In A. E. Watson, G. H. Aplet, and J. C. Hendee, (Comps.), Personal, societal, and ecological values of wilderness: Sixth World Wilderness Congress proceedings on research, management, and allocation, Volume 1. (pp. 79-84). USDA Forest Service Proceedings RMRS-P-4. Ogden, UT: Rocky Mountain Research Station.

McIntyre, N. \& Roggenbuck, J. W. (1998). Nature/person transactions during an outdoor adventure experience: a multiphasic analysis. Journal of Leisure Research, 30, 401-422.

Muir, J. (1901). Our National Parks. San Francisco, CA: Sierra Club Books.

Muir, J. (1911). My First Summer. Boston, MA: Houghton Mifflin.

Muir, J. (1916). A Thousand-Mile Walk to the Gulf. Boston, MA: Houghton Mifflin.

Norusis, M. J. (1994). SPSS Advanced Statistics 6.1. Chicago, IL, SPSS Inc.

Olson, S. F. (1956). The Singing Wilderness. New York: Knopf.

Olson, S. F. (1963). Runes of the North. New York: Knopf.

Olson, S. F. (1969). Open Horizons. New York: Knopf.

Olson, S. F. (1976). Reflections from the North Country. New York: Knopf.

Patterson, M. E., Williams, D. R., Watson, A. E., \& Roggenbuck, J. R. (1998). An hermeneutic approach to studying the nature of wilderness experiences. Journal of Leisure Research, 30 , 423-452.

PohI, S. L., Borrie, W. T., \& Patterson, M. E. (2000). "Women, Wilderness and everyday life: A documentation of the connection between wilderness recreation and women's everyday lives." Journal of Leisure Research, 32, 415-434.

Samdahl, D. M. (1988). A symbolic interactionist model of leisure: theory and empirical support. Leisure Sciences, 10, 27-39.

Samdahl, D. M. (1991). Issues in the measurement of leisure: A comparison of theoretical and connotative meanings. Leisure Sciences, 13, 33-49. 
Samdahl, D. M. (1992). Leisure in our lives: exploring the common leisure occasion. Journal of Leisure Research, 24, 19-32.

Samdahl, D. M. \& Kleiber, D. A. (1989). Self-awareness and leisure experience. Leisure Sciences, $11,1-10$.

Scherl, L. M. (1989). Self in wilderness: understanding the psychological benefits of individual -wilderness interaction through self-control. Leisure Sciences, 11, 123-135.

Scherl, L. M. (1990). The wilderness experience: a psychological evaluation of its components and dynamics. In A. T. Easley, J. F. Passineau \& B. L. Driver (Compilers), The use of wilderness for personal growth, therapy, and education. (pp. 11-26). USDA Forest Service General Report RM-193. Fort Collins, CO: Rocky Mountain Forest Experiment Station.

Stevens, J. (1992). Applied Multivariate Statistics for the Social Sciences, Second Edition. Hillsdale, NJ: Lawrence Erlbaum.

Stewart, W. P. (1992). Influence of the onsite experience on recreation experience preference judgments. Journal of Leisure Research, 24, 185-198.

Stewart, W. P. (1998). Leisure as multiphase experiences: Challenging traditions. Journal of Leisure Research, 30, 391-400.

Sudman, S., Bradburn, N. M. \& Schwarz, N. (1996). Thinking about Answers: The application of cognitive processes to survey methodology. San Francisco, CA: Jossey-Bass.

Talbot, J. F. \& Kaplan, S. (1986). Perspectives on wilderness: re-examining the value of extended wilderness experiences. Journal of Environmental Psychology, 6, 177-188.

Thoreau, H. D. (1854). Walden. Boston, MA: Ticknor \& Fields.

Thoreau, H. D. (1862). Walking. In Civil Disobedience $\mathcal{E}^{2}$ Other Essays. Mincola, NY: Dover Publications.

Vento, B. F. (1990). A wilderness revolution for the 1990's. In D.W. Lime (ed.) Managing America's Enduring Wilderness Resource. (pp 9-17). St. Paul, MN: Minnesota Extension Service, University of Minnesota.

Warren, K. (1990). The power and promise of ecological feminism. Environmental Ethics. 12, 125-146. 